\title{
Hacia el sistema político justo: diálogo Robert Alexy y Tomás De Aquino*
}

\section{To the Political System Justice: Robert Alexy, Dialogue and Thomas Aquinos}

Fecha de recepción: 1 de septiembre de 2009

Fecha de aprobación: 23 de septiembre de 2009

\author{
Carlos Alberto Cárdenas Sierra**
}

\section{Resumen}

Para el positivismo basta con que el sistema de reglas sea efectivo. Para el "no positivista" Alexy no basta: se hace necesario buscar la conexión conceptual entre Derecho y moral -que es la que justifica el respeto a los miembros del pueblo-. Tomás de Aquino está de acuerdo con Alexy en esa interconexión, en cuanto a que un sistema injusto se convierta en "sistema jurídico". No lo admitiría, a menos que sea provisionalmente, si tal sistema ("tiranía") resultara soportable y se previera que si lucha contra él, se hace peor, o se sustituye por otro más injusto. El auténtico sistema jurídico, como armadura del sistema político justo, es aquél que, sustentado en la exigencia moral de la naturaleza humana, es expresión de los reclamos de las inclinaciones naturales del hombre.

\section{Palabras clave}

Estado constitucional, maximidad iusfundamental, no positivismo, universalia iuris, constitución mixta, optimum animalium, esfera jurídica, naturaleza de la cosa.

Este artículo corresponde a una sección del resultado de la investigación Filosofía iuspolítica tomasiana en diálogo con la filosofía iuspolítica contemporánea: Tomás de Aquino en diálogo con: Bobbio, Chomsky, Rawls y Alexy.

** Docente investigador adscrito al Centro de Investigaciones Socio-jurídicas Francisco de Vitoria de la Facultad de Derecho de la Universidad Santo Tomás; líder del grupo de Investigación Raimundo de Peñafort; miembro de la Sociedad Internacional Tomás de Aquino; docente-tutor de la Maestría en Derecho Público de la USTA- Konstanz. Correo electrónico: torreondomingo@gmail.com 


\begin{abstract}
For the positivism, it is enough that the system of rules is effective. For the non positivist Alexy it isn't enough. It is necessary to find the conceptual link between Law and Moral, which is the one that justify the respect into the community. Tomás agrees with Alexy on that association. When an unfair system becomes a "juridical system" it wouldn't admitted, unless if that system (tyranny) turning on to be manageable and there was foreseen that, fighting against it, was done worse or replacing by more unfair other one. The authentic juridical system, as an armor of the political system, is that sustained in the moral exigency of the human nature, is an expression of the claims of the natural inclinations of the man.
\end{abstract}

\title{
Key words
}

Constitutional State, non positivism, mixed constitution.

\section{EL ESTADO CONSTITUCIONAL DEMOCRÁTICO EN ALEXY}

\section{El modelo alemán'}

El jusfilósofo y justeórico Alexy no reduce su obra a la Teoría de la argumentación jurídica. Es decir, no se resignó a quedarse solamente con la carreta olvidándose de los bueyes; él mismo insiste que, desde el principio, su teoría se enmarcaba en una teoría general del Estado con sistema jurídico perfecto -por contener catálogo de derechos fundamentales- (Alexy, 1998, pp. 28-29), es decir, que la carreta se construiría a la medida de los bueyes. Por su desempeño como investigador y profesor de Derecho Público, su mirada filosófica siempre se ha fijado en los problemas de la justificación del Estado, convirtiendo en paradigmático el Estado Constitucional Democrático de la República Federal de Alemania, que tiende a influir cada vez más en Europa, puesto que fomenta el desarrollo, en los países vecinos, de una teoría y una praxis constitucionales más o menos comunes, con rastros en Hispanoamérica a través de España.

Para el jusfilósofo de Kiel, el Estado constitucional democrático modélico se caracteriza por seis principios fundamentales, que recogen una prolongada experiencia histórica, cuyas raíces hay

1 Basado en R. Alexy (s.f, en Carbonell, 2003, p. 31 ). que rastrear en el judeo-cristianismo, los estoicos y los filósofos del Estado de la Modernidad, hasta alcanzar las declaraciones de derechos de Virginia (1776) y de los franceses (1789): dignidad humana, libertad, igualdad; estos principios condicionan: la estructura, los fines del Estado y el Derecho democrático y social. A su vez, la estructura, los fines del Estado y el Derecho democrático y social definen las condiciones y los límites históricos de la dignidad humana, la libertad y la igualdad, aspectos que generan tensiones entre aspiraciones y posibilidades reales.

\section{La "maximidad" iusfundamental"}

Alexy atiende prioritariamente la dignidad humana, la libertad y la igualdad, es decir, al aspecto iusfundamental que da sentido a la estructura y los fines del Estado de Derecho con pretensión de ser democrático y social. Sin la presencia de los derechos fundamentales señalados, no se puede aspirar a fundar democracia auténtica ni a dimensionar los fines sociales. De ahí que estos tres aspectos gocen de maximidad, tanto en el sistema jurídico alemán como en los sistemas jurídicos de su zona de influencia. Aunque las prácticas la nieguen; también la maximidad es proclamada por muchos sistemas jurídicos periféricos, que cuentan casi siempre con flamantes

2 Basado en R. Alexy (s.f., en Carbonell, 2003, pp. 33-35). 
Cortes constitucionales. La maximidad atribuida a los derechos fundamentales reviste cuatro formas: máximo rango, máxima fuerza, máximo contenido y máxima indeterminación.

\begin{tabular}{|c|c|c|c|c|}
\hline \multicolumn{2}{|c|}{ Máximo } & & \multicolumn{2}{|c|}{ Máxima } \\
\hline rango & 1 & $\leftarrow$ & 2 & fuerza \\
\hline & $\begin{array}{l}\hat{\imath} \\
\vdots \\
\vdots\end{array}$ & & $\uparrow$ & \\
\hline Máxima & 4 & $-----\rightarrow$ & 3 & Máximo \\
\hline indeterm & nación & & & contenido \\
\hline
\end{tabular}

El esquema anterior muestra que las maximidades máximo rango, máxima fuerza y máximo contenido interactúan y se potencian entre sí; pero que la máxima indeterminación parece tener una función debilitante, sugerida por las flechas discontinuas. En consecuencia, es necesario explicar brevemente cada maximidad:

- Máximo rango dentro del sistema jurídico, dada la dignidad constitucional iusfundamental. Cualquier norma inferior que desconozca los derechos fundamentales se hace inconstitucional y, por ello, nula.

- Máxima fuerza dentro del sistema jurídico, porque el plexo iusfundamental subordina como derecho vigente directo al legislativo, al ejecutivo, al judicial y a todos los demás órganos menores de poder.

- Máximo contenido, porque el objeto iusfundamental goza de centralidad como principio y criterio de organización social.

- Máximo grado de indeterminación, por la formulación sucintageneral, de escasa concreción de los derechos fundamentales.

Esta maximidad de indeterminación es lo que constituye la debilidad aplicativa del plexo iusfundamental, así éste goce de las demás maximidades. Pero, esa indeterminación, frente a la precisión detallada de un estatuto de tráfico o de un decreto de impuestos, es al mismo tiempo el resorte de la necesidad imperiosa de interpretar por parte de todos los operadores jurídicos. Esta necesidad que no se puede descartar genera una lucha por el Derecho, que reclama el arbitraje continuo de un Tribunal Constitucional, el cual debe aceptar las "mejores razones" en un campo en el que no se puede pretender la razón única.

La cuarta maximidad es la que ha justificado la explicitación de una teoría de la argumentación jurídica, al servicio prioritario de la determinación iusfundamental, a fin de llegar a consensos acerca de la verdad o la justicia para fundar toda decisión en todos los niveles operativos de la jerarquía del sistema, aspecto normativo del aparato de poder que es el Estado constitucional democrático.

\section{Lucha por la interpretación y democracia ${ }^{3}$}

La lucha por la interpretación iusfundamental no se puede dar, sino en un Estado democrático, en cuyo seno el pluralismo hace valer las distintas pretensiones, desde diversas concepciones morales, de tal manera que las razones ciudadanas permitan pactar, sin que el asunto quede librado a mayorías simples, excluyentes de minorías débiles. Se deben interpretar los derechos fundamentales de manera que se pueda proteger lo que todos Ios ciudadanos consideran importante de la perspectiva de una moral pública, que "pone de manifiesto una representación común sobre las condiciones justas de cooperación social" (Alexy, s.f., en Carbonell, 2003, p. 40).

A fin de que la mayoría parlamentaria no se arrogue la facultad de consensuar políticamente en nombre de un "todos" abstracto, al que pretende representar por efecto del voto, un Tribunal Constitucional debe retomar argumentativamente tanto la ley como las aspiraciones y expectativas colectivas.

3 Basado en R. Alexy (s.f., en Carbonell, 2003, pp. 37-41). 
Hay que plantearse, pues, qué es aquello que ciudadanos racionales con concepciones personales del bien distintas consideran como condiciones de cooperación social justa tan importantes como para que el simple Legislador no pueda decidir sobre ello. En esta cuestión se halla al mismo tiempo la clave para una posible reconciliación del principio democrático con los derechos fundamentales (Lexy, s.f., en Carbonell, 2003).

La "representación argumentativa de los ciudadanos" logrará fundamentar decisiones plausibles, probables, así se pretenda el máximo rigor y la mayor corrección. Sobre ello Aristóteles alertaba en la Ética a Nicómaco y lo enfatizaba el Aquinate en su Comentario (L. I, cap. 3) y en el Tratado de la Ley: "No puede buscarse en todas las cosas la misma certeza".

\section{Fundamentabilidad iusfundamental ${ }^{4}$}

La importancia de las normas iusfundamentales para el sistema jurídico de un Estado depende de su fundamentalidad formal y de su fundamentalidad material. La primera resulta de su posición en la cúspide de la estructura del ordenamiento, vinculante de todos los poderes del Estado y la segunda depende de la formulación de contenidos explícitos, de los cuales se pueden derivar nuevos contenidos. La Constitución deberá ser mixta, pero se pueden dar dos extremos: el formalismo puramente procedimental, que da más importancia a la organización y los procedimientos que a lo sustantivo iusfundamental; $y$ el modelo puramente material, que daría primacía a los contenidos sobre los procedimientos decisorios. La primera justificaría como derecho positivo cualquier decisión, sin que los derechos fundamentales logren fuerza vinculante. La segunda, convertiría a los operadores en órganos declarativos de lo que se conoce. La fundamentalidad, pues, es formalmaterial para que desempeñen un papel central en el sistema jurídico.

$4 \quad$ Basado en R. Alexy (2002, p. 503-506).

\section{Carácter del sistema jurídico ${ }^{5}$}

La irradiación de las normas iusfundamentales en todas las gradas de la pirámide jurídica tiene tres efectos de gran importancia para determinar el carácter del sistema jurídico:

- Limitación de los contenidos del derecho ordinario, si no por determinación, sí por exclusión o incompatibilidad.

- Apertura semántica de las disposicionesiusfundamentales y su carácter de principios, lo que exige procedimiento ponderativo.

- El sistema jurídico es un sistema abierto frente a la moral, al asumir los conceptos básicos iusfundamentalesmateriales de dignidad, libertad e igualdad, bases del concepto de justicia, derivaciones positivizadas de la evolución moral occidental.

\section{"No positivismo" y apertura a la moral}

Al considerar el sistema jurídico abierto frente a la moral, Alexy se reconoce como "no positivista", frente al positivismo "puro", por ejemplo, el kelseniano. Pero no es un "no positivismo" radical. En diálogo con el Aquinate, aclara:

El concepto de derecho no positivista más radical surge de la sustitución completa de la eficacia social y de la legalidad conforme al ordenamiento por la corrección moral. Sería una teoría iusnaturalista pura. En la práctica, tal teoría iusnaturalista pura radical conduciría al anarquismo. Por ello, iusnaturalistas serios como Tomás de Aquino subrayan la necesidad del derecho positivo definido mediante la legalidad conforme al ordenamiento y la eficacia social (ST, I-II, 90, 3, 4; 91, 3; 95, 1; II-II, 57, 2).

De ahí que la cuestión decisiva no sea si el derecho ha de definirse o conjuntamente por la eficacia social y la legalidad conforme al ordenamiento o por la corrección moral, sino más bien si la eficacia social y la legalidad conforme al

$\overline{5 \text { Basado en R. Alexy }}$ (2002, p. 524). 
ordenamiento han de estar, de un modo u otro, vinculadas o no con la corrección moral (Alexy, 2005, p. 20).

Basta con analizar la definición de ley del Aquinate para hallar también en éste la interdependencia entre eficacia social, legalidad y corrección moral.

El elemento de la "corrección", que resulta esencial para establecer el concepto integral del Derecho, consiste en incluir la búsqueda de la justicia, que pertenece al ámbito moral, aunque no lo cubre, sino en lo que concierne a la alteridad. En diálogo con Aristóteles, Ulpiano y Tomás, Alexy aclara:

La fórmula clásica según la cual la justicia consiste en dar a cada uno lo suyo: "ius suum cuique tribuere" pone de manifiesto que el objeto de la justicia no es todo el ámbito de la moral, sino sólo la parte que se ocupa de la distribución y la compensación (Alexy, 2005, p. 55).

Y concluye: "Una vez constatado que la justicia trata de la distribución y la compensación, inmediatamente se descubre una definición genérica de justicia: justicia es corrección en relación con la distribución y la compensación" (Alexy, 2005, p. 57). Y sigue explicando:

Que la justicia sea un caso especial de corrección tiene profundas implicaciones para la teoría de la justicia. Quien afirma que algo es justo, afirma siempre, al mismo tiempo, que es correcto. Quien afirma que algo es correcto, da a entender que es fundamentable. De este modo, la tesis de la justicia como corrección conduce, directamente, a la justicia como fundamentabilidad. Establece una intrínseca relación entre el concepto de justicia y el de fundamentabilidad (Alexy, 2005, p. 58).

A continuación añade: "Las cuestiones de justicia son cuestiones normativas. Esto significa que la justicia como fundamentabilidad se ocupa de la fundamentabilidad de normas sobre la distribución y la compensación en el sentido expuesto" (Alexy, 2005, p. 58).

\section{Espacio-tiempo de los sistemas jurídicos y "universalia iuris"}

Los Estados y sus sistemas jurídicos existen espacio-temporalmente, lo cual implica contingencia, particularidad, relatividad, aspectos resaltados por el positivismo. Los "no positivistas" radicales resaltan lo que hay de universal o necesario en el derecho, los universalia ante leges o los universalia in legibus.

El "no positivista" moderado que es Alexy intenta responder equilibradamente, sentando once tesis:

- Los relativistas y los universalistas tienen parcialmente razón.

- Existenrasgosdistintivosquetododerechodebe poseer (algunos universalia iuris).

- No puede existir sistema jurídico si no existe prohibición u obligación.

- Todos los sistemas jurídicos o bien incluyen potestades o capacidades jurídicas públicas y privadas, o bien tienden a incluirlas.

- Todas las normas y las decisiones jurídicas, así como todos los sistemas jurídicos, formulan necesariamente una pretensión de corrección.

Esta pretensión no es una pretensión específicamente jurídica. Está enraizada en todo tipo de razonamiento, y en la medida en que razonar, esto es, afirmar, debatir y preguntar, es un componente necesario de la forma humana de vida, se funda en la naturaleza humana (Alexy, 2005, p. 73).

- En la pretensión de corrección hay que tener en cuenta el concepto de contingencia reflexi$v a$, que fuerza a atender la relación derecho y temporalidad, es decir, a vincular los elementos contingentes y los elementos universales.

- " "E]xiste un núcleo de derechos humanos básicos que poseen validez eterna" (Alexy, 2005, p. 75), para todos los seres humanos con independencia del tiempo y del espacio. 
- "[L]asnormasjurídicas debidamentepromulgadas y socialmente eficaces que son incompatibles con el núcleo de los derechos humanos básicos son extremadamente injustas y, por tanto, no son derecho" (Alexy, 2005, p. 76).

- "[L]o contingente es necesario para lo universal" (Alexy, 2005, p. 84): contingencia jurídica y seguridad jurídica.

- " "L]a identidad de un sistema jurídico racional está determinada tanto por proposiciones universalescomo por proposicionescontingentes" (Alexy, 2005, p. 85).

- La omnipresencia de la pretensión de corrección y del discurso en el sistema jurídico no implica que se desvanezca el carácter relativo y contingente de la mayor parte del derecho, pero supone que la contingencia no es pura facticidad. Es una contingencia reflexiva, que, de una parte, es relativa al tiempo y, de otra, trasciende el tiempo, en tanto aspira a la realización de la idea regulativa deverdad o corrección práctica (Alexy, 2005, p. 87).

\section{El contenido nuclear de todo sistema jurídico}

A pesar de la contingencia y relatividad de los Estados, en el interior de cada sistema jurídico hay un "mínimo" de moralidad integrado por Ios Derechos Humanos básicos como objeto de justicia, que asegura la corrección de todos los discursos que fundamentan las decisiones de los operadores jurídicos. Así, la Constitución, al consagrar ese núcleo se convierte en el núcleo formal-material de todo el sistema jurídico y de la estructura política del Estado social y democrático de Derecho.

José Antonio Seoane (uno de los traductores y presentadores de Alexy) concluye:

El carácter nuclear de la Constitución revalida la importancia de los derechos humanos, en su forma de derechos fundamentales. Así mismo, favorece que las normas de justicia tengan estructura de principios, más flexible que la de las reglas, y que la ponderación aparezca como el gozne metodológico de la teoría de la justicia (Seoane, 2005, p. 9).

\section{De un orden "injusto" a un auténtico "sistema jurídico"}

Utilizando la ficción de un estadio originario en que se vive bajo la "ley del más fuerte", Alexy imagina cómo se podría pasar de un "orden injusto" a otro que se aproxima a la idea de "sistema jurídico viable". Entre distintos análisis del fenómeno estatal, Alexy da importancia al examen de la idea de sistema político injusto, que podría evolucionar a través del sistema de reglas hacia un auténtico sistema jurídico. Opina que el "argumento de la injusticia" puede "referirse a normas individuales de un sistema jurídico o al sistema jurídico en su totalidad" (Alexy, 1998, p. 43). En cuanto a las normas individuales, el conflicto se soluciona sopesando los valores de justicia y de seguridad jurídica, en cuanto resultado de una consideración normativa y no conceptual. Sobre sistemas jurídicos considerados en su totalidad, hay que decir que lo que es correcto para una norma individual, no lo es automáticamente para el sistema jurídico integral (Alexy, 1998, p. 46), porque es preciso distinguir entre "conexiones fácticas" $y$ "conexiones conceptuales" (Alexy, 1998, p. 47).

Hay dos tipos de órdenes sociales que no pueden ser sistemas jurídicos por razones conceptuales, sin importar si tienen o no validez: primero, el orden sin sentido, como en el caso de que unas personas sean regidas por un grupo de forajidos, quienes ni revelan sus intenciones al establecer reglas ni permiten la seguridad necesaria para que los súbditos busquen con certeza sus intereses. Los súbditos no tienen derechos y viven bajo el terror, además, obedecen órdenes cambiantes, caprichosas o imposibles (Alexy, 1998, p. 47). La única regla estable es que los bandidos pueden hacer lo que les venga en gana. La segunda forma de orden es el predatorio (Alexy, 1998, p. 47), cuando los foraji- 
dos se "transforman en bandidos organizados con prohibición de violencia, jerarquización entre los bandidos y el sistema de reglas para los súbditos para continuar su explotación (ordenada)" (Alexy, 1998, p. 47).

A la larga, el sistema predatorio evoluciona, por su propia dinámica, superando las intenciones primitivas de los bandidos; pero éstos quieren seguir en el poder y entonces procuran legitimarse y legitimar el sistema. Se van convirtiendo en legisladores creadores de un sistema de reglas que enmascaran el régimen de explotación, lo que les permite afirmar que sus prácticas sirven a un fin superior: el desarrollo del pueblo (justicia y progreso social, seguridad democrática). Así, va naciendo un referente que funda un mínimo de "pretensión de corrección".

Es posible matar y robar, en cualquier momento, a cualquier súbdito para alcanzar los propósitos de la explotación de los dirigentes. Sin embargo, los gobernantes son castigados si no matan o roban de acuerdo con cierta forma, por ejemplo, mediante la decisión de tres miembros del grupo dominante; y si sus actos no están públicamente justificados por el propósito de desarrollar al pueblo. La mayoría de los súbditos aceptan esta justificación, y la mayoría de los gobernantes también creen en ella.

No se puede dudar, ese "sistema de reglas" es perfectamente injusto; pero no es "conceptualmente imposible llamarlo 'sistema jurídico'" (Alexy, 1998, p. 47). No por las reglas mismas; no por el sistema; no porque el sistema otorgue ventajas para todos. La clave está -al sentir de Alexy- en que ha surgido la "pretensión de corrección", que le impone a todos ceñirse al sistema y conectarlo con la moral procedimental universalista, que supone la posibilidad de que todos intervengan como iguales para justificar sus opciones, posibilidad implícita en la finalidad del sistema: "el desarrollo del pueblo". Para el positivismo basta con que el sistema de reglas sea efectivo. Para el "no positivista" Alexy, no basta: se hace necesario buscar la conexión conceptual entre derecho y moral (que es la que justifica el respeto a los miembros del pueblo).

Tomás está de acuerdo con Alexy en esa interconexión. En cuanto a que un sistema injusto se convierta en "sistema jurídico", no lo admitiría, a no ser provisionalmente, si tal sistema ("tiranía") resultara soportable y se previera que, luchando contra él, se hiciera peor o fuera sustituido por otro más injusto. El auténtico sistema jurídico, como armadura del sistema político justo, es aquél que, sustentado en la exigencia moral de la naturaleza humana, es expresión de los reclamos de las inclinaciones naturales del hombre. Para el Aquinate, la ley inicua no es Derecho (ST. II-II, 57, 2). Sólo se puede considerar justo el sistema político, si su sistema jurídico regula la búsqueda de las cosas necesarias para la perfección humana (RP, L., C. 6.; ST., I-II, 90, 2), es decir, para la "vida buena" (In Pol. L. I, lec. 1) de todos, aun de los bandidos, que nunca podrían ser legitimados para ejercer el poder, ni convertirse en legisladores, y a quienes habría que aplicar todo "el peso de la ley" -incluso al extremo de tener que recurrir a la cirugía amputadora: cercenar el miembro gangrenado.

Frente a Alexy, Tomás insistía en que el paso de un sistema injusto a un sistema justo no es meramente conceptual, por el hecho de que el nuevo concepto reúna formalmente las notas de la idea de régimen justo. Para un realista, el sistema justo lo será conceptualmente cuando los conceptos estén fundados en realidades. La verdad sigue siendo adecuación entre el entendimiento y la cosa; si no, se cae en la ficción política, en la ficción jurídica, en la mentira integral. Widow Lira acota:

La principal mentira política, y en cierto sentido, a la que se reducen todas las otras, pareciera ser aquélla que se manifiesta en la afirmación que dice que la humanidad del hombre está en que él mismo define esa humanidad. Es decir, la humanidad es algo perfectamente indeterminado, algo que al fin de cuentas dependerá completamente de los deseos 
individuales de cada cual o, a lo más, de la suma de dichos deseos. En términos prácticos, esto significa desconocer cualquier fin inscrito en las inclinaciones naturales más profundas del hombre (2004, p. 287).

Aunque Tomás acepta soportar temporalmente, para evitar males mayores, un sistema depredatorio, éste no se depura de manera meramente conceptual, esto es, porque surja en él la "pretensión de corrección". Es necesario que esta corrección apunte a las exigencias de la naturaleza humana, "pretensión de corregir" todas las formas de inhumanidad. Widow Lira remata:

Los sistemas o regímenes políticos de los últimos dos siglos pareciera que fundan su propia libertad en el hecho de negar cualquier fin natural al hombre, respecto del cual, en consecuencia, él tenga un apetito natural que no depende de sí. La negación de fines naturales de la vida humana equivale a negar la posibilidad misma de una verdad moral o política, por cuanto ya no hay ningún punto de referencia que permita establecer la rectitud del apetito que es, a su vez, la medida del entendimiento (2004, p. 287).

\section{EL "ESTADO CONSTITUCIONAL DEMOCRÁTICO" EN EL AQUINATE}

\section{La mejor Constitución}

Sin duda, en Tomás de Aquino no encontramos la expresión "Estado constitucional democrático" con el alcance que le da el "neoconstitucionalismo". Por otra parte, el siglo XIII aún no percibía el Estado como lo percibió Maquiavelo y como evolucionó hasta la actualidad desde el siglo XVI, para llegar a convertirse en "poder institucionalizado" o en "institución de las instituciones", superando las formas de "poder individualizado". Pero, en Tomás hallamos los elementos mínimos para el diálogo con los "neoconstitucionalistas":

- Su politia (latinización de la politeia griega) se proyecta como alternativa a los regímenes puros: monarquía, aristocracia, democracia.
- La politia ideal es un "régimen mixto", que combina los principios de los tres regímenes puros, a fin de evitar los riesgos tiránicos de los regímenes puros.

- La "buena constitución" establece jerarquía en el ejercicio de la potestas, pero su base es democrática: "todos tengan alguna participación en el gobierno, todos sean los dueños de tal poder tanto porque puedan ser elegidos cualesquiera del pueblo, como porque deban ser elegidos por todos" (ST, I-II, 105, 1).

- El "régimen mixto" no es producto del azar o la voluntad de los bandidos, sino creación jurídica por medio de la ley (ST, I-II, 105, 1).

- La ley que crea el régimen, en cuanto ordinatio rationis, supone que todos los miembros de la comunidad tienen racionalidad, dignidad, libertad, igualdad, etc., pues de lo contrario no podrían "participar", ser "dueños" del poder, ni podrían ejercer su voluntad electiva, ni podrían ser dignos de elección...

Sin duda, porque la Doctrina Social de la Iglesia católica se ha desarrollado, en gran parte, como prolongación de doctrinas tomistas. El pontífice Benedicto XVI, en su última Encíclica: Caritas in veritate, de junio de 2009, considera oportuno salir en defensa del Estado constitucional frente a las pretensiones de anti-estatismo de la globalización:

La sabiduría y la prudencia aconsejan no proclamar apresuradamente la desaparición del Estado. Con relación a la solución de la crisis actual, su papel parece destinado a crecer, recuperando muchas competencias... La ayuda internacional [...] debería apoyar en primer lugar la consolidación de los sistemas constitucionales [...] reforzar las garantías propias de un Estado de derecho, un sistema de orden público y de prisiones respetuoso de los Derechos Humanos y a consolidar instituciones verdaderamente democráticas $(C V, \mathrm{n} 41)$. 


\section{La "buena constitución" no parte del "homo homini lupus"}

Toda organización de la sociedad política ("régimen mixto" o su evolución estatal), según el Aquinate, responde a la profunda necesidad de posibilitar la convivencia y la coexistencia entre seres racionales impulsados tanto por la virtud como por la pasión ciega, lo que explica por qué un individuo puede presentarse como optimum animalium (el mejor de los animales) o como pessimum animalium (el peor de los animales). El jusfilósofo tomista Giuseppe Graneris comenta:

Luego quien se proponga gobernar a los hombres no debe suponer que ha de domar fieras ni que tendrá que acariciar angelitos; debe saber en cambio que ha de guiar a un ser bueno, capaz de volverse diabólico. Quien se deja persuadir por el tétrico pesimismo hobbesiano, no puede ver en el Estado otra cosa que una máquina inventada para aplastar la libertad humana, fatalmente malvada; pero como esta máquina nació ella misma del seno de esa maldad, no puede ser sino su monstruoso engrandecimiento, y de ahí que su misión sea la de sofocar al individuo superándolo en malicia y violencia. En cambio, si nos abandonamos al pueril optimismo de Rousseau, entonces no descubriremos en el Estado más que un idílico acuerdo entre gentes incapaces de chocarse; y su finalidad será necesariamente la de promover el descubrimiento y el desarrollo de tantos hermosos tesoros escondidos en la libertad humana. Ésta es la tarea del Estado en las diversas formas de liberalismo.

Graneris señala la falsedad del reduccionismo antropológico, que opta por la presunción de bestialidad radical o por la angelicalidad absoluta; frente a esos extremos excluyentes. El realismo tomista afirma la unidad integral del ser humano:

Las dos posiciones son falsas, por unilaterales. La filosofía perenne es más realista y comprensiva. El Estado existe porque el hombre es malo; pero también existe porque el hombre es bueno [...]; tiene una misión compleja, que debe tender a frenar la malicia y estimular la bondad, no conduciendo al hombre ni al sacrificio ni al abuso, sino al uso razonable de su libertad (Graneris, 1973, pp. 163-164).

\section{Estado y Derecho}

Para lograr frenar las perversiones y estimular la bondad, el Estado, producto de la ley, cuenta, ante todo, con instrumentos externos, entre los cuales el primero es el ordenamiento jurídico. Éste funda al Estado, pero luego se convierte en su legítima forma de ejercer coerción (freno) y coacción (estímulo) para coordinar armónicamente las relaciones intersubjetivas. Graneris explica:

No nos hagamos ilusiones; los instrumentos que el Estado sabe manejar con destreza -y no puede menos que hacer así- son los medios de la coerción. Entre ellos el primer puesto lo tiene el ordenamiento jurídico. Rechazamos las fórmulas de Kant, de Ihering, de Kelsen, que establecen una perfecta igualdad entre el derecho, la facultad de constreñir, el Estado; negamos la equivalencia de estos tres términos, especialmente cuando bajo ella se quiera esconder la pretensión estatal del monopolio del derecho y de la coerción, hasta despojar a toda otra sociedad del poder de dictar normas jurídicas, es decir, obligantes y compulsivas. Pero reconocemos que estos tres términos están unidos por una estrecha afinidad. El Estado tiene tendencia a transformar en derecho todo lo que toca. Diría que el derecho es la forma tendencialmente obligada de la acción del Estado; el derecho, digo, como ordenamiento social, con su necesario acompañamiento de jueces y tribunales, de cárceles y carceleros, de patíbulos y verdugos (Graneris, 1973, p. 165).

\section{Derecho y moral}

El Aquinate acepta la importancia del Derecho que sirve al Estado; pero no está de acuerdo en que éste monopolice todo el Derecho, pues no está en su competencia absorber la totalidad nomológica (ley eterna, ley natural, ley divina, ley humana). El mismo Derecho Positivo es más que el Derecho 
estatal, puesto que el ius gentium lo desborda. El ordenamiento jurídico, regulador del poder del Estado, que opera como su fuente originaria y como su motor, no está librado al voluntarismo de los intereses preponderantes, sino que depende de la "corrección" que le ofrece su fuente moral:

[...] para Santo Tomás, el centro o la base del fenómeno jurídico es una cosa; en otras palabras es algo objetivo y no subjetivo, como sería la facultad y como podría ser también la ley, reducida al arbitrio del legislador. Aprendemos, además, que el orden jurídico está esencialmente anclado en el orden moral, porque la cosa en torno a la que gravita no es una cosa cualquiera, sino es la cosa justa, o sea, aquella misma cosa que es regulada por la virtud de la justicia. Objetividad y eticidad del mundo jurídico son, pues, las dos primeras lecciones que aprendemos de Santo Tomás (Graneris, 1979, pp. 82-83).

En el ordenamiento jurídico hay que distinguir distintos niveles, a partir de las exigencias de la esencia dinámica del ser humano ("naturaleza humana") (ST, 2003, p. 16), pasando por las conclusiones inmediatas de la razón especulativo-práctica, hasta alcanzar el nivel último del legislador positivo y de los ejecutores y aplicadores de los distintos estatutos normativos. Implícitos en todo ordenamiento jurídico laten los reclamos de la naturaleza humana ("todo aquello hacia lo que el hombre tiene inclinación natural, la razón lo capta como bueno, y por tanto como algo que debe lograr con su acción") (ST, I-II, 94, 2). Esas inclinaciones se traducen como preceptos de la "ley natural", que se imponen al legislador humano como ley que está más allá de su arbitrio.

\section{La esfera jurídica y su "núcleo"}

Graneris, interpretando a Tomás, representa el mundo jurídico en forma de esfera, en cuyo núcleo actúan los preceptos de la ley natural:

Al centro está un núcleo constituido por preceptos dotados de naturalidad pura y evidente. Son normas jurídicas per se, resultantes de la naturaleza de las cosas de manera tan clara e imperativa que no puede caber duda alguna ni exigir un raciocinio para ser conocidas o reconocidas. Es la zona de lo que es justo "ex sui natura... secundum absolutam sui considerationem"; es la zona del derecho natural intuitivo, inmutable, universal en el pleno sentido de la palabra... Este núcleo está rodeado de una zona media, que recoge normas de una naturalidad menos clara y no reconocibles como tales sino a través de un trabajo de raciocinio. Sigue siendo la naturaleza que habla y que impera; pero su voz no se manifiesta directamente; debe ser copiada, interpretada, elaborada por la razón humana; y ésta, para pronunciarse, debe atender no sólo al objeto inmediato de la acción, sino a sus circunstancias y a sus consecuencias. Es la zona de lo que todavía es justo por naturaleza, pero "secundum aliquid quod ex ipso consequitur", ya no más de un modo absoluto ni intiuitivo. Es el plano en el cual el pensamiento jurídico procede imitando el modo científico, partiendo de premisas naturales y deduciendo sus conclusiones necesarias.

Inmediatamente continúa Graneris:

En la superficie de la esfera encontramos una tercera zona, a la que la naturaleza hace llagar aún su voz, pero en la que ni la intuición ni el razonamiento logran ya discernir preceptos determinados. Son sólo sugerencias genéricas que, para llegar a convertirse en reglas de vida social, exigen ser precisadas. Es la zona que en el lenguaje empírico se llama derecho positivo, porque todo aparece dejado al arbitrio legislativo. La mirada del filósofo descubre aún allí lo que puede ser llamado la enervación natural, en cuanto el legislador no puede hacer otra cosa que trabajar sobre la base de las sugerencias de la naturaleza. Los antiguos decían que él procede aquí "per modum determinationis" o también "per modum artis", en cuanto no concluye, como en el caso precedente, sino que escoge uno entre tantos modos posibles de determinar lo indeterminado (Graneris, 1979, pp. 145-146). 
En el núcleo de la esfera jurídica se distinguen tres aspectos de la vida del hombre: el plano físico, que funda el precepto de la conservación de sí mismo; el plano sensitivo, que funda el precepto de la conservación de la especie y el origen de la familia; y el plano racional, que funda el precepto tanto de la necesidad de conocer la verdad como de vivir en sociedad (ST. I-II, 94, 2). Esos preceptos radicales sirven después de base necesaria para todas las reglas que la razón práctica va estableciendo, según las demandas históricas de cada generación humana. Los preceptos nucleares no alcanzan a indicar los detalles para definir cómo conservar la vida personal, ni cómo conservar la familia (si poligámica o monogámica), ni cómo acceder a la verdad, ni cómo organizar cada comunidad humana.

\section{La fundamentación de los "derechos fundamentales"}

Desde esta perspectiva, la fundamentación de los "derechos fundamentales" no podría depender simplemente del mandato de la voluntad de poder, sino que supone el hecho de que el legislador traduce como ordinatio rationis las conclusiones de la ley natural. El legislador, para positivar los derechos fundamentales, y los juristas y aplicadores, para definir el alcance, la jerarquía y la conmensurabilidad o inconmensurabilidad de éstos, deben partir siempre de las exigencias renovadas del interior de la esfera, dato que un realista debe tener como decisivo de la verdad jurídica: "adecuación" de la razón práctica a la "naturaleza de la cosa", tal como se presenta al conocimiento, según los desarrollos y los recursos de todas las formas de razón: filosófica, científica, teológica, técnica...

La inteligencia no se puede inventar qué es el hombre, sino acoger humildemente los datos de la existencia (esse) en que éste se va manifestando; y la función racional no puede hacer otra cosa que respetar los datos de la inteligencia como punto de partida. La vida, la racionalidad, la libertad, la dignidad, la igualdad, etc. no pueden ser "decisiones" de conveniencia desde el poder, sino incontrastables demandas ontológicas. La vida o la dignidad no son concesiones, y su ampliación a toda persona humana no es una mera conquista de fuerzas políticas o revoluciones, sino imperativo que fluye del hecho de que todos los racionales "son hombres", como reclamaban los frailes tomistas de La Española con la voz de fray Antón de Montesinos en 1511. Las reglas del discurso práctico general de Alexy parecen fundarse en esa convicción. La regla de razón: "quien pueda hablar puede tomar parte en el discurso", sin duda supone: "quien pueda pensar puede hablar". De esa racionalidad universal se desprende la "dignidad" (excelencia o superioridad sobre los demás entes), la igualdad, la libertad, etc.

\section{REFERENCIAS}

Aquino, T. (2003). Del Ente y de la Esencia. Buenos Aires: Losada.

Aquino, T. Suma Teológica. (1988: I Tomo; 1989: II Tomo; 1990: III Tomo; 1994: IV y V Tomos). Dirigida por los Regentes de Estudios de las Provincias Dominicanas de España, Madrid: BAC.

Aquino, T. (1967). Suma Contra Gentiles (Texto latino al cuidado de la Orden de Predicadores con traducción y notas introductorias de L. Robles Carcedo, O.P., A. Robles Sierra, O.P., y J.M. De Garganta, O.P., $2^{\mathrm{a}}$ edición). Madrid: BAC.

Aquino, T. (2003). La Monarquía. Al Rey de Chipre (o Régimen de los Príncipes) en Opúsculos y Cuestiones Selectas (A. Ossuna Fernández-Largo, Coord.). Madrid: BAC (Maior). (1998). Notas de Fernández-Largo y Ángel Chueca. En la edición de Barcelona: Altaya. (Mismas publicadas por Ed. Tecnos en 2000).

Aquino, T. (2001). Opúsculos y cuestiones selectas. Texto latino al cuidado de la Orden de Predicadores con traducción y notas de Juan Manuel Almarza 
Meñica, Abelardo Lobato y Antonio Osuna Fernández-Largo, entre otros. Madrid: BAC (2 Tomos).

Aquino, T. \& de Alvernia, P. (2001). Comentario a la Política de Aristóteles (A. Mallea, Trad. y prólogo; M. y C. A. Lértora, notas). Pamplona: EUNSA.

Alexy, R. (2003) Los derechos fundamentales en el Estado constitucional democrático. En M. Carbonell. Neoconstitucionalismo(s). Madrid: Trotta.

Alexy, R. (1998). Derecho y razón práctica. México: D. Fontamara.
Alexy, R. (2002). Teoría de Ios Derechos Fundamentales. Madrid: CEPC.

Alexy, R. (2005). La institucionalización de la justicia. Granada: Comares.

Graneris, G. (1973). Contribución tomista a la filosofía del derecho. Buenos Aires: EUDEBA.

Graneris, G. (1979). La filosofía del derecho a través de su historia y sus problemas. Santiago de Chile: EJ-Chile.

Widow L., J.L. (2004). La naturaleza política de la moral. Santiago: RIL. 